\title{
Vocal Communication in Androgynous Territorial Defense by Migratory Birds
}

\author{
Eugene S. Morton ${ }^{1,2}$ and Bridget J. M. Stutchbury ${ }^{2}$ \\ ${ }^{1}$ Hemlock Hill Field Station, 22318 Teepleville Flats Road., Cambridge Springs, PA 16403, USA \\ ${ }^{2}$ Department of Biology, York University, Toronto, ON, Canada M3J 1P3
}

Correspondence should be addressed to Eugene S. Morton, mortone@si.edu

Received 2 November 2011; Accepted 4 December 2011

Academic Editors: T. Monnin and V. Tilgar

Copyright (C) 2012 E. S. Morton and B. J. M. Stutchbury. This is an open access article distributed under the Creative Commons Attribution License, which permits unrestricted use, distribution, and reproduction in any medium, provided the original work is properly cited.

\begin{abstract}
Many temperate zone breeding birds spend their non-breeding period in the tropics where they defend individual territories. Unlike tropical birds that use song for breeding and non-breeding territorial defense, vocal defense differs strikingly between breeding and non-breeding territories in migrants. Song, restricted to males, is used during defense of breeding territories but callnotes are used to defend non-breeding territories. To explain why callnotes and not songs predominate in the non-breeding context, we present an empirical model based upon predictions from motivational/structural rules, ranging theory and latitudinal differences in extra-pair mating systems. Due to sex role divergence during breeding that favors singing in males, but not females, females may be unable to range male song. Ranging requires a signal to be in both the sender and receiver's repertoire to allow the distance between them to be assessed (ranged). Non-breeding territories of migrants are defended by both males and females as exclusive individual (androgynous) territories. Ranging Theory predicts callnotes, being shared by both males and females can, in turn, be ranged by both so are effective in androgynous territoriality. Where songs are used for non-breeding territorial defense both sexes sing, supporting the evolutionary significance of shared vocalizations in androgynous territorial defense.
\end{abstract}

\section{Introduction}

A continuing challenge in evolution is to identify the sources of selection acting on signal structure in vocal communication. Research has recently shifted from an emphasis on information transfer, wherein the sender's goals determine signal structure, to the receiver's goals (e.g., [1]). Under the receiver control model, receiver assessment of signals feeds back to the sender by influencing what the sender's signals have accomplished [2-4]. Assessment insures that signals are honest and allows us to identify results of sexual conflict (Sensu [5]). Here, we provide an example of how signal assessment can produce seasonal signal structure changes in the same individuals in the context of territorial defense.

Many migrant birds are territorial in temperate-zonebreeding areas and resume territorial behavior when they reach nonbreeding areas. They are, in essence, territorial throughout the year but breeding and nonbreeding territories are widely separated, often thousands of kilometers apart, in space as well as in time [6].

There are major changes in territorial behavior between breeding and nonbreeding periods that affect the context of communication. While breeding, the roles of the sexes of most migrant species are usually highly differentiated with males singing and defending territories, while females, build nests and incubate eggs. In the migrant's tropical nonbreeding period, females and males that have nonbreeding territories defend them against any and all conspecifics regardless of gender (androgynous territoriality) [6, 7]. Female mate selection and male territoriality often result in males being larger than females; thus, sexual selection during the breeding period often induces sexual inequality in the nonbreeding period when it comes to defending territories [8-10]. Both periods of territoriality interact with territorial 
habitat quality in the long nonbreeding period to produce important carry over effects on reproductive success $[11,12]$. The evolutionary context of communication changes from one dominated by sexual selection to one dominated by natural selection and sexual conflict. How have these changes affected vocal communication involved in territorial defense?

Here, we describe the changes in signals used in breeding and androgynous territoriality and in species that switch from breeding territoriality to nonterritorial nonbreeding social systems. To explain the evolution of signal changes in the two contexts, it is necessary to approach the question from two aspects, although they interact. One is concerned with the changes in signal categories used in breeding versus. androgynous territoriality, and the second concerns the physical structure of these signals. For signal categories, we apply ranging theory and for signal structure, we apply motivation-structural rules. Ranging describes selection on long-distance signals derived from perception of the distance and location of a sound's source [13]. Motivation-structural rules predict signal structures in a two-dimensional mosaic in a motivational gradient from highly aggressive to fearful (or friendly) $[3,14]$.

\section{A Priori Predictions from Two Models}

2.1. Ranging Theory Predictions. After a sound leaves a bird's mouth, it begins to change in the relative amplitudes of its mix of sound frequencies, reverberation, and amplitude. When a bird hears a sound, it perceives these features of acoustical degradation and uses them to estimate its distance to the sound's origin. It can do this because the amount of degradation correlates with distance $([13,15]$ reviewed in [16]). Distance assessment compares the degraded signal with one in the receiver's own neural song control system (memory) [13, 17-19], perhaps via mirror neurons in the HVC song center [20].

How does a bird use this distance assessment mechanism to defend its territory? If the assessor can range the signal, it knows how close it is to the defender. A signal that is simply detectable can be ignored but one that "sounds close" cannot be ignored. For a signal to sound close, it must be in the assessor's memory so that the defender can use the assessor's own distance assessment mechanism to threaten it [13]. The widespread use of matched countersinging is a familiar example of territory defenders using the ranging ability of intruders to threaten them [20,21].

Singing is a male-only trait in most temperate zone passerines [22], used for repelling other males and attracting females as mates and extra pair partners (reviewed in [23]). In contrast, when these same birds defend their tropical androgynous territories they exclude all conspecifics. Song is not efficient in androgynous territorial defense because the nonsinging female gender may be incapable of ranging song [13]. Furthermore, males from diverse areas in the breeding range have different songs. When males converge in the tropics, a given male's song may not be in the repertoire of other males he is attempting to repel. As songs are perceived categorically, parts of songs or phrases that are shared between dialects probably would not permit ranging [24]. Therefore, ranging theory predicts that song will not be favored for androgynous territorial defense because many intruders will not be able to range songs and so cannot be threatened by singing. Ranging predicts that vocalizations shared among all members of a species would be favored.

2.2. Motivation-Structural Rules Predictions. Ranging of songs has been studied but call notes are used in a great many contexts, for example, in mobbing, alarming, or in contact, so vary greatly in structure. If ranging involves shared sound types how should call notes used as territorial vocalizations be structured, given their great variation in contextual usage? The motivation/structural rules (M-S) model $[3,14]$ provides a model. M-S rules tie the sender's motivation to the physical structure of calls. To briefly summarize this relationship, an aggressive bird use low-pitch and harsh sounds whereas friendly, fearful, or appeasing birds use high pitch and tonal sounds. This dichotomy represents motivational "endpoints", used when communication is about to end and the animal is on the verge of fight or flight. Most communication events lie somewhere between these endpoints and most vocalizations do too. Sounds between the endpoints contain a mix of both: they rise and fall in pitch and appear chevron-like in spectrograms $[3,25]$.

A common avian call note with this intermediate structure and is often described, onomatopoetically, as chip. We call them "barks" here, as a general term, to exemplify their similarity in function and structure to a dog's bark. In androgynous territorial defense, barks fulfill all the requirements for ranging that song does not. They are shared by all conspecifics and, as a consequence, males and females from all populations may be able to range distance when hearing them. Barks, often used periodically, with no need for exogenous stimulation, are a form of tonic communication [26], that reduce intrusions and save energy in territory defense [27]. Barks can be motivationally "neutral" or tend towards motivation endpoints by changing in frequency and sound quality to signify changes in aggressiveness [3]. Barks are also rife with degradation cues for ranging because their frequency sweeps are ideal for producing reverberation [28]. Barks can be produced with high source amplitude (loudly) and bark amplitude may be useful for ranging [29]. The predictions from ranging theory and M-S rules coincide in predicting that vocal defense of androgynous territories is mediated through call notes, particularly motivationally "neutral" barks.

\section{Methods}

We documented vocalizations used by migratory passerine birds during the nonbreeding season in the course of field work in Panama, Mexico, Cuba, Venezuela, and Colombia over the last 40 years. We also queried colleagues who were familiar with certain species and consulted field guides to use their standardized onomatopoetic renditions of call notes or song that we documented were used for nonbreeding territorial defense. We classified species into the general 
social categories of territorial or flocking with a few sharing both attributes due to changes in behavior coincident with tropical dry or wet seasons [7]. Territorial species were defined as those whose members defend an area for 2 mo or more during the nonbreeding period. "Flocking" species refer to those occurring in conspecific social groups to distinguish these from species that, although they join mixed species flocks, exhibit territorial defense because they defend these flocks against joining by other conspecific individuals. We defined three categories of vocalizations, song, bark, and growl based upon their physical structure as defined by M-S rules discussed above. Song was defined as a longer, mainly tonal, vocalization [30]. We compiled our observations for four speciose families of New World passerines (tyrannids, turdids, vireonids, and parulids) and two species of thraupids (recently considered to be cardinals by [31]) using the avian classification in Howard and Moore [32].

\section{Results}

Our data contained $18 \mathrm{New}$ World flycatcher species (tyrannids), six thrushes (turdids), nine vireos (vireonids), 39 New World warblers (parulids), and two species of cardinals in the genus Piranga. Both songs and call notes were used. Most of the flycatchers (64\%) used barks, all of the thrushes and warblers $(100 \%)$, and none of the vireos $(0 \%)$ used barks for defending territories (Table 1). The data are not phylogenetically independent, so we compare within and between genera in each family. Of the five genera representing the flycatehers, all members of one (Contopus, three species) used song, the eight Empidonax all used barks, one of the two Sayornis used a bark but the other used song, the single member of Myiarchus used song, and all four Tyrannus used barks. The flycatchers were territorial except for the four Tyrannus, which occurred in flocks. Species in the two thrush genera used barks as did all members of the 12 warbler genera represented in the sample (Lovette et al. [33] revised warbler genera, but our conclusions are unaffected). Most of the vireos used growls, but one used song. The territorial vireos used sequences, sometimes species-specific of growls, but the three flocking vireos used single growls. The territorial summer tanager (Piranga rubra) used barks, but the flocking species is quiet, according to two field biologists familiar with the scarlet tanager $(P$. olivacea) in its South American nonbreeding area.

Barks are the most common vocalizations used in longdistance territorial defense (Table 1). An example of a bark is shown in Figure 1. Acadian flycatchers (Empidonax virescens) repeat these call notes about 25 times per minute on their tropical territories in Panama, particularly at dawn and dusk (unpublished data).

\section{Discussion}

The ranging model succeeded in predicting that vocalizations used in territorial defense would be shared by both sexes during androgynous territoriality in birds. Sharing by both sexes was the major generality for there was much

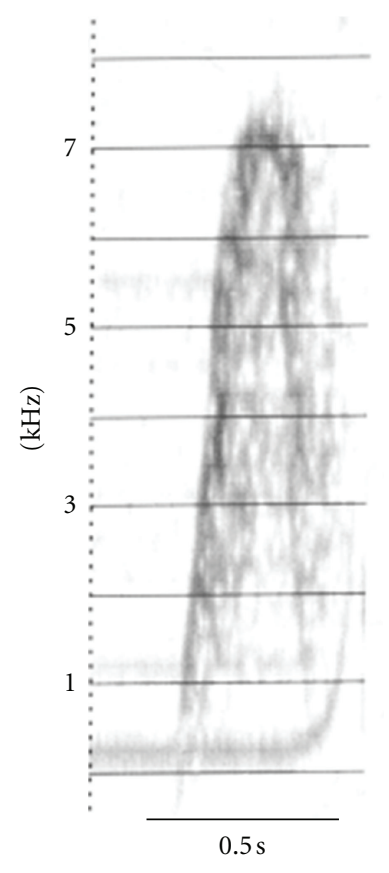

FIgURE 1: Territorial call note of an Acadian flycatcher (Empidonax virescens) from Panama showing the chevron-shape characteristic of barks. Note the "mossy" appearance due to reverberations arriving at the microphone slightly later than the directly transmitting sound.

variation in type of vocalization. Most species used shared barks but some used song or growls, also shared by both sexes, and there was a definite influence of phylogeny (Table 2).

5.1. Barking Vocalizations. The motivation-structural rules model predicted that call note structures would be motivationally neutral barks or growls. A territory holder could repel intruders simply by making its presence known by using any species-specific vocalization. Barks used to defend territories, like song, seem to occur either endogenously or as a specific response to an intruder. Why are barks, rather than song, the predominate form of vocalization used in territorial defense?

Perhaps an answer is that, unlike most song, which is tied to a mate choice context, barks are freed to vary in structure to symbolize motivation. They may lower in pitch or be uttered more rapidly (e.g., Kentucky warbler (Geothlypis formosus), [34], pers. obs.) (Figure 2). On their tropical nonbreeding territories, hooded warblers (Wilsonia citrina) bark in a regular cadence, but when given during border, confrontations are delivered more rapidly, culminating in rapidly delivered chippity-chups or "stuttering" barks, so rapid that it appears as though more than a single bird is giving them (Figure 3 ). If this fails, and they are face to face, the defender utters low and harsh growls, zrrr, the aggressive endpoint predicted by M/S rules and attacks [35]. 


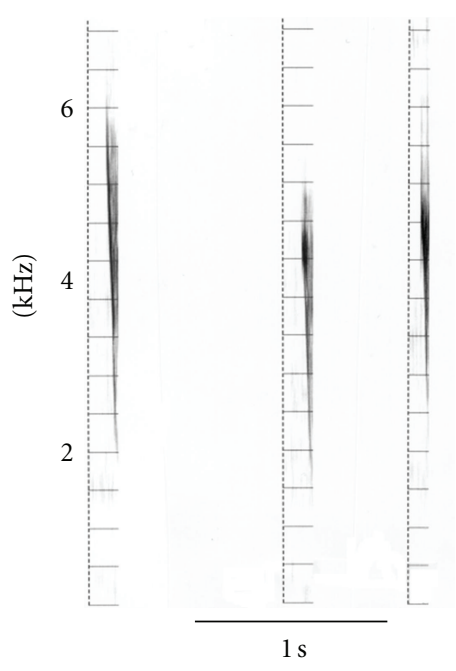

Figure 2: Three consecutive barks from a Kentucky warbler (Oporornis formosus) showing changes in frequency range. In response to playback or territorial intrusion, this species uses a lower-pitch range of call notes, as predicted by motivationstructural rules (see text).

The chevron structure of barks makes the compass direction of the caller known to listeners [36]. But all of these useful attributes are found in other vocalizations, such as song, so other causes for the abundant use of barks by migrant birds must be at work. We believe the evidence supports the idea that vocalizations found in all individuals, including the variation in call notes described above, can be ranged by all individuals and so are efficacious in defending nonbreeding territories. The widespread use of barks is predicted by motivation-structural rules because such "motivationally neutral" territorial signals can be endogenously produced to defend territories. Such production repels potential intruders, reducing the frequency of actual intrusion and saving energy and foraging time.

5.2. Growling Vocalizations. Not all groups of birds use barks for nonbreeding territory defense. Barks are not used by vireos, breeding, or nonbreeding. Instead, vireo produce a series of growl-like calls used all year. In yellow-throated vireos (Vireo flavifrons), a series of growls are given, as stereotyped in delivery as songs, with a descending pitch and slowing cadence (cha-cha-cha-cha cha chaa..chaa chaaa). Both sexes use this "chatter growl" to repel conspecifics from the interspecific canopy flocks they defend during the nonbreeding period. Blue-headed vireos (Vireo solitarius) also growl but theirs lack a stereotyped sequence. Instead, they are variable in pitch and repetition rate.

We point out the great contrast between the vireos that defend winter territories and those that do not. The red-eyed vireo (Vireo olivaceus) and Philadelphia vireo ( $V$. philadelphicus) tend to join mixed species flocks composed of highly frugivorous species. Neither species appears to defend a flock against conspecifics. These vireos are silent, except for occasional alarm notes, nyaah in the case of the red-eyed. Philadelphia vireos are partial to joining greenlet flocks (Hylophilus minor) in Panama, and it is difficult for an observer to tell vireos and greenlets apart. The Piranga cardinals exhibit similar adaptations in nonbreeding vocalizations. The summer tanager ( $P$. rubra) maintains territories defended with barks whereas, the social flocking scarlet tanager (P. olivacea) remains silent (Table 1).

5.3. Singing in Overwinter Territorial Defense. As an exception to the "bark, do not sing" rule, many territorial vireos sing, as well as growl, during the nonbreeding season. Because vireos sexes are indistinguishable in the field, perhaps this nonbreeding singing is performed only by males. However, for one species, the white-eyed vireo (Vireo griseus), females are known to sing in defense of winter territories [37]. Female White-eyed vireos do not sing during the breeding season. Typically, their winter songs begin with barks. These barks are all mimetic, derived from thrushes and flycatchers and other species that use barks for nonbreeding territorial defense (pers. obs.). Male breeding songs do not incorporate mimetic barks. Perhaps these borrowed barks are useful in repelling other species from the Bursura fruit, this species depends upon for winter survival [38]. In one of the few systematic playback studies of overwintering birds, Greenberg et al. [38] found that white-eyed vireos overwintering on the Yucatan Peninsula and resident mangrove vireos (Vireo pallens) respond more to playbacks of one another's chatter growls than to playbacks of songs, which differ greatly in the two species. Perhaps these growls, because they are closer to the aggressive endpoint of $\mathrm{M}$ $S$ rules are less species-specific than barks, and therefore, evoke more interspecific responses, useful in defense of fruit resources against other vireo species.

Vireos that sing in nonbreeding territorial defense, the first seven vireo species in Table 1, compose a subgenus whose members share the morphological patterns of eye rings and wing bars [39]. Only males sing during the breeding season but, hormonally, males have low testosterone levels throughout the breeding season and prolactin levels equivalent to that of females, at least in blue-headed vireos [40]. Sex roles during reproduction have converged relative to most temperate zone breeding songbirds, with males building nests and incubating eggs, coupled with genetic monogamy [18]. Females choose mates that invest heavily in parental care and then abandon care of fledged young to these parentally-oriented males [41]. We suggest that the hormonal convergence that underlies theirs unusually, for temperate zone breeding species, similar sex roles are related to the use of song by both genders during androgynous territoriality. Of course, we offer this as a stimulus for further research.

5.4. Other Trends in Overwintering Communication. Resident and migratory yellow warblers (Dendroica petechia) illustrate divergence in territorial vocalizations. Overwintering migrant yellow warblers are highly territorial both intraand inter-specifically $[42,43]$. Intraspecifically, the resident "mangrove" forms of the yellow warbler have dealt with 
TABLE 1: Nonbreeding vocalizations in five families of Nearctic-Neotropical migrant passerines ${ }^{\mathrm{a}}$.

\begin{tabular}{|c|c|c|c|}
\hline Family/species & Social behavior & Vocalization & Song, bark, or growl ${ }^{\mathrm{b}}$ \\
\hline \multicolumn{4}{|l|}{ Tyrannidae } \\
\hline Contopus borealis & Territorial & whip-whip-whip & Song \\
\hline C. sordidulus & Territorial & preer & Song \\
\hline C. virens & Territorial & pweee' & Song \\
\hline Empidonax flaviventris & Territorial & pweet & Bark \\
\hline E. virescens & Territorial & whees & Bark \\
\hline E. alnorum & Territorial & peet & Bark \\
\hline E. trailii & Territorial & whip & Bark \\
\hline E. minimus & Territorial & pwit & Bark \\
\hline E. hammondii & Territorial & peek & Bark \\
\hline E oberholseri & Territorial & wit & Bark \\
\hline E. wrightii & Territorial & wit! & Bark \\
\hline Sayornis phoebe & Territorial & chip! & Bark \\
\hline S. sayi & Territorial & pee-ee & Song \\
\hline Myiarchus crinitus & Territorial & weeep & Song \\
\hline Tyrannus vociferans & Flocking & chip-eer' & Bark $^{\mathrm{c}}$ \\
\hline T. verticalis & Flocking & whit & Bark \\
\hline T. tyrannus & Flocking & keer & Bark \\
\hline T. forficatus & Flocking & $k i p$ & Bark \\
\hline \multicolumn{4}{|l|}{ Turdidae } \\
\hline Catharus fuscescens & Territorial (?) & pwick & Bark \\
\hline C. minimus & Territorial & peew & Bark \\
\hline C. bicknelli & Territorial & beer & Bark $^{\mathrm{d}}$ \\
\hline C. ustulatus & Territorial (?) & quirt & Bark \\
\hline C. guttatus & Territorial & chuck & Bark \\
\hline Hylocichla mustelina & Territorial & putt-putt-putt & Barks \\
\hline \multicolumn{4}{|l|}{ Vireonidae } \\
\hline Vireo griseus & Territorial & chip chip chareechick & Song \\
\hline V. bellii & Territorial & cha cha cha, and so forth. & Growls \\
\hline V. atricapillus & Territorial & $?$ & $?$ \\
\hline V. vicinior & Territorial & cha-cha-cha-chrr chrr & Growl/song \\
\hline V. solitarius & Territorial & cha-cha-cha-chrr chrr & Growls \\
\hline$V$. flavifrons & Territorial & che-che-che-che cha cha & Growls/song \\
\hline V. gilvus & Flocking & eeah & Growl \\
\hline V. philadelphicus & Flocking & ehhh & Growl \\
\hline V. olivaceus & Flocking & nyaah & Growl \\
\hline \multicolumn{4}{|l|}{ Parulidae } \\
\hline Vermivora pinus & Territorial & chip, bzzt-bzzt-bzzt & Barks \\
\hline V. chrysoptera & Territorial & chip, bzzt-bzzt-bzzt & Barks \\
\hline$V \cdot$ peregrina & Flock/territory & chip/zzrt & Bark/growl \\
\hline V. celata & Territorial & chip & Bark \\
\hline V. ruficapilla & Territorial & chip & Bark \\
\hline Parula americana & Flocking & chip & Bark \\
\hline Dendroica petechia & Territorial & $\begin{array}{l}\text { chip..chip..chip, and so } \\
\text { forth. }\end{array}$ & Bark \\
\hline D. pensylvanica & Territorial & chup & Bark \\
\hline D. magnolia & Territorial & quince & Bark \\
\hline
\end{tabular}


TABle 1: Continued.

\begin{tabular}{|c|c|c|c|}
\hline Family/species & Social behavior & Vocalization & Song, bark, or growl ${ }^{\mathrm{b}}$ \\
\hline D. tigrina & Territorial & chip & Bark \\
\hline D. caerulescens & Territorial & chip & Bark \\
\hline D. coronata & Flocking & chup & Bark \\
\hline D. virens & Flocking & chip & Bark \\
\hline D. chrysoparia & Territorial & chip & Bark \\
\hline D. fusca & Flocking & chip & Bark \\
\hline D. dominica & Territorial & chip & Bark \\
\hline D. pinus & Territorial & chip & Bark \\
\hline D. kirtlandii & Territorial & chip & Bark \\
\hline D. discolor & Territorial & chip & Bark \\
\hline D. palmarum & Territorial & chit & Bark \\
\hline D. castanea & Flock/Territory & chip & Bark \\
\hline D. striata & Flock/Territory & chip & Bark \\
\hline D. cerulea & Territorial & chip & Bark \\
\hline Mniotilta varia & Territorial & buzzy chips & Barks \\
\hline Setophaga ruticilla & Territorial & chip & Bark \\
\hline Protonotaria citrea & Flocking & chip & Bark \\
\hline Helmitheros vermivorus & Territorial & chip & Bark \\
\hline limnothlypis swainsonii & Territorial & chip & Bark \\
\hline Seiurus aurocapillus & Overlapping & chit & Bark \\
\hline S. noveboracensis & Territorial & chinki & Bark \\
\hline S. motacilla & Territorial & chink & Bark \\
\hline Oporornis formosus & Territorial & chip, chup, chink & Bark \\
\hline O. agilis & Territorial & chip & Bark \\
\hline O. philadelphia & Territorial & chunk & Bark \\
\hline O. tolmei & Territorial & chunk & Bark \\
\hline Geothlypis trichas & Territorial & chup & Bark \\
\hline Wilsonia citrina & Territorial & chink & Bark \\
\hline W. pusilla & Territorial & chick & Bark \\
\hline W. canadensis & Territorial & chip & Bark \\
\hline \multicolumn{4}{|l|}{ Thraupidae } \\
\hline Piranga rubra & Territorial & kitticut & Bark \\
\hline P. olivacea & Flocking & nonvocal & Mostly quiet ${ }^{\mathrm{d}}$ \\
\hline
\end{tabular}

${ }^{a}$ Data for both sexes, collected by authors unless otherwise noted.

${ }^{\mathrm{b}} \mathrm{See}$ text for description of these vocal categories.

${ }^{\mathrm{c}} \mathrm{I}$. Bisson, pers. com.

dJ. Townsend, pers. com.

${ }^{\mathrm{e}} \mathrm{R}$. Greenberg and J. Ahern, pers. com.

TABle 2: Frequency of use of barks by both sexes of species in four taxonomic groups that defend nonbreeding territories.

\begin{tabular}{lc}
\hline Flycatchers $\Longrightarrow(64 \%)$ & (14 species) \\
Thrushes $\Longrightarrow(100 \%)$ & (6 species) \\
Warblers $\Longrightarrow(100 \%)$ & (39 species) \\
Vireos $\Longrightarrow(0 \%)$ & ( 9 species $)$ \\
\hline
\end{tabular}

the territorial birds from northern breeding populations in two ways. Their bark has diverged from the northern birds' sharp chip! to become a soft chup. Such chip divergence is found in other subdominant warbler species. Magnolia warbler (Dendroica magnolia) barks sound like quince quince, a bark that sounds to the human ear very different from the sharp bark of the yellow warbler, and would probably not evoke aggression in dominant territorial yellow warblers.

While migrant birds often rely on barks for defense of nonbreeding territories, there are many exceptions (Table 1). We have suggested a model, a combination of ranging theory and $\mathrm{M}-\mathrm{S}$ rules to predict and to explain why call notes and not songs are used in the non-breeding context for 


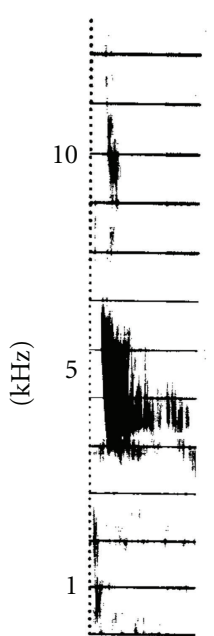

(a)

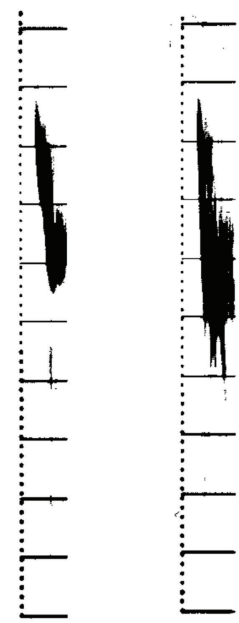

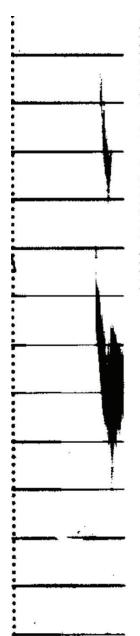

(b)

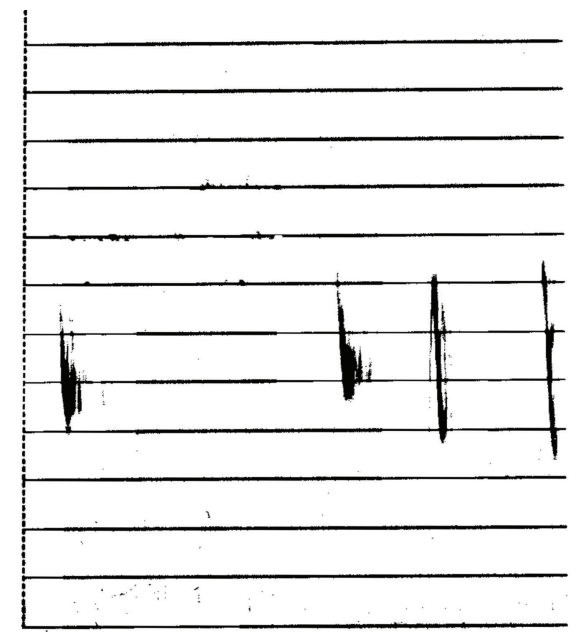

(c)
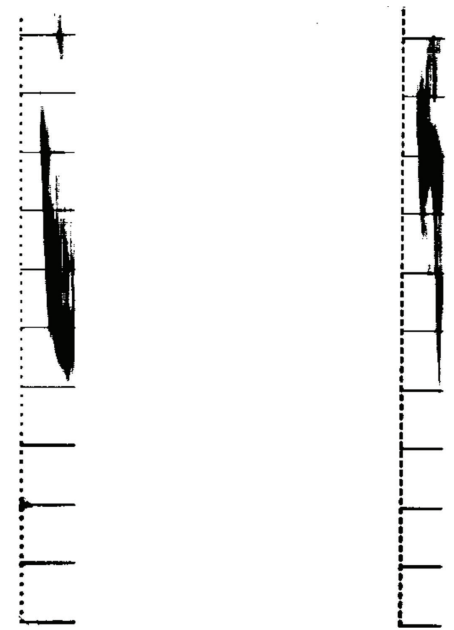

(d)

Figure 3: Hooded warblers (Wilsonia citrina) use a rich variety of call notes to defend nonbreeding territories. In the upper row, the left hand bark (a) shows reverberation. The upper central figure (b) shows the reverse chevron (down then up), a species-specific characteristic of barks given spontaneously in territorial maintenance. This is followed by a series of rapid call notes (chippity chups; (c)), highly variable in structure, used by aggressive individuals before attacking specific rivals. The four lower call notes (d) are from breeding individuals. Barks are used in defense of nestlings, and the high-pitch chevron note on far right shows and elevated frequency typically given by adults when a predator is near the nest.

most species. The empirical data would seem to support the predictions from these models, but there is much variability in the types of vocalizations used in androgynous territoriality that remain to be described.

The efficacy of the ranging and motivation-structural rules models to predict androgynous territorial vocalizations can and should be tested with species in other temperate/tropical migratory bird systems.

\section{Acknowledgments}

The authors thank the Smithsonian Institution Scholarly Studies Program and NSERC for support and the staff of the Smithsonian Tropical Research Institute for their help in many ways. Two anonymous reviewers offered many suggestions to improve the paper.

\section{References}

[1] E. Font and P. Carazo, "Animals in translation: why there is meaning (but probably no message) in animal communication," Animal Behaviour, vol. 80, no. 2, pp. e1-e6, 2010.

[2] T. Guilford and M. S. Dawkins, "Receiver psychology and the evolution of animal signals," Animal Behaviour, vol. 42, no. 1, pp. 1-14, 1991.

[3] D. H. Owings and E. S. Morton, Animal Vocal Communication: A New Approach, Cambridge University Press, Cambridge, UK, 1998. 
[4] E. S. Morton, R. G. Coss, and D. H. Owings, "Mitogenetic rays and the information metaphor," in Animal Communication Theory: Information and Influence, U. E. Stegmann, Ed., Cambridge University Press, Cambridge, UK, In press.

[5] G. Arnqvist and L. Rowe, Sexual Conflict, Princeton University Press, Princeton, NJ, USA, 2005.

[6] J. H. Rappole, The Ecology of Migrant Birds, Washington, DC, USA, 1995.

[7] E. S. Morton, "Adaptations to seasonal changes by migrant land birds in the Panama Canal Zone," in Migrant Birds in the Neotropics: Ecology, Behavior, Distribution, and Conservation, A. Keast and E. S. Morton, Eds., pp. 437-453, Smithsonian Institution Press, Washington, DC, USA, 1980.

[8] P. P. Marra and R. T. Holmes, "Consequences of dominancemediated habitat segregation in American Redstarts during the nonbreeding season," Auk, vol. 118, no. 1, pp. 92-104, 2001.

[9] B. J. M. Stutchbury, E. S. Morton, and T. E. Pitcher, "Sex roles in migrants: extra-pair mating systems and winter social systems," in Birds of Two Worlds: The Ecology and Evolution of Migratory Birds, R. Greenberg and P. Marra, Eds., pp. 307-320, Johns Hopkins University Press, Baltimore, Md, 2005.

[10] E. S. Morton, "Habitat segregation by sex in the hooded warbler: experiments on proximate causation and discussion of its evolution," American Naturalist, vol. 135, no. 3, pp. 319333, 1990.

[11] D. R. Norris, P. P. Marra, T. K. Kyser, T. W. Sherry, and L. M. Ratcliffe, "Tropical winter habitat limits reproductive success on the temperate breeding grounds in a migratory bird," Proceedings of the Royal Society B: Biological Sciences, vol. 271, no. 1534, pp. 59-64, 2004.

[12] D. R. Norris, "Carry-over effects and habitat quality in migratory populations," Oikos, vol. 109, no. 1, pp. 178-186, 2005.

[13] E. S. Morton, "Predictions from the ranging hypothesis for the evolution of long distance signals in birds," Behavior, vol. 99, no. 1-2, pp. 65-86, 1986.

[14] E. S. Morton, "On the occurrence and significance of motivation-structural rules in some bird and mammal sounds," American Naturalist, vol. 3, pp. 855-869, 1977.

[15] D. G. Richards, "Estimation of distance of singing conspecifics by the Carolina wren," Auk, vol. 98, pp. 127-133, 1981.

[16] P. K. McGregor, "Sound cues to distance: the perception of range," in Perception and Motor Control in Birds, M. N. O. Davies and P. R. Green, Eds., pp. 74-94, Springer, Berlin, Germany, 1994.

[17] E. S. Morton, "Why songbirds learn songs: an arms race over ranging?" Poultry and Avian Biology Reviews, vol. 7, no. 1, pp. 65-71, 1996.

[18] E. S. Morton, B. J. M. Stutchbury, J. S. Howlett, and W. H. Piper, "Genetic monogamy in blue-headed vireos and a comparison with a sympatric vireo with extrapair paternity," Behavioral Ecology, vol. 9, no. 5, pp. 515-524, 1998.

[19] E. S. Morton, J. Howlett, N. C. Kopysh, and I. Chiver, "Song ranging by incubating male Blue-headed Vireos: the importance of song representation in repertoires and implications for song delivery patterns and local/foreign dialect discrimination," Journal of Field Ornithology, vol. 77, no. 3, pp. 291-301, 2006.

[20] J. F. Prather, S. Peters, S. Nowicki, and R. Mooney, "Precise auditory-vocal mirroring in neurons for learned vocal communication," Nature, vol. 451, no. 7176, pp. 305-310, 2008.
[21] J. R. Krebs, R. Ashcroft, and K. V. Orsdol, "Song matching in the great tit Parus major L," Animal Behaviour, vol. 29, no. 3, pp. 918-923, 1981.

[22] E. S. Morton, "A comparison of vocal behavior among tropical and temperate passerine birds," in Ecology and Evolution of Acoustic Communication in Birds, D. E. Kroodsma and T. E. Miller, Eds., pp. 258-268, Cornell University Press, Ithaca, NY, USA, 1996.

[23] B. J. M. Stutchbury and E. S. Morton, Behavioral Ecology of Tropical Birds, Academic Press, London, UK, 2001.

[24] J. F. Prather, S. Nowicki, R. C. Anderson, S. Peters, and R. Mooney, "Neural correlates of categorical perception in learned vocal communication," Nature Neuroscience, vol. 12, no. 2, pp. 221-228, 2009.

[25] E. S. Morton, "An evolutionary view of the origins and functions of avian vocal communication," Japanese Journal of Ornithology, vol. 49, pp. 69-78, 2000.

[26] W. M. Schleidt, "Tonic communication: continual effects of discrete signs in animal communication systems," Journal of Theoretical Biology, vol. 42, no. 2, pp. 359-386, 1973.

[27] J. R. Krebs, "Song and territory in the great tit Parus major," in Evolutionary Ecology, B. Stonehouse and C. Perrins, Eds., pp. 47-62, MacMillon, London, UK, 1977.

[28] D. G. Richards and R. H. Wiley, "Reverberations and amplitude fluctuations in the propagation of sound in a forest: implications for animal communication," American Society of Naturalists, vol. 115, pp. 381-399, 1980.

[29] B. S. Nelson, "Avian dependence on sound pressure level as an auditory distance cue," Animal Behaviour, vol. 59, no. 1, pp. 57-67, 2000.

[30] D. A. Spector, "Definition in biology: The case of 'bird song," Journal of Theoretical Biology, vol. 168, no. 4, pp. 373-381, 1994.

[31] J. Klicka, K. Burns, and G. M. Spellman, "Defining a monophyletic Cardinalini: a molecular perspective," Molecular Phylogenetics and Evolution, vol. 45, no. 3, pp. 1014-1032, 2007.

[32] R. Howard and A. Moore, The Howard and Moore Complete Checklist of the Birds of the World, Princeton University Press, Princeton, NJ, USA, 2003.

[33] I. J. Lovette, J. L. Pérez-Emán, J. P. Sullivan et al., “A comprehensive multilocus phylogeny for the wood-warblers and a revised classification of the Parulidae (Aves)," Molecular Phylogenetics and Evolution, vol. 57, no. 2, pp. 753-770, 2010.

[34] S. Mabey, Demography and territorial behavior of wintering Kentucky Warblers in Panama, M.S. thesis, University of Maryland, College Park, Md, USA, 1992.

[35] E. S. Morton, J. F. Lynch, K. Young, and P. Mehlhop, "Do male Hooded Warblers exclude females from nonbreeding territories in tropical forests?" Auk, vol. 104, pp. 133-135, 1987.

[36] P. Marler, "Characteristics of some animal calls," Nature, vol. 176, no. 4470, pp. 6-8, 1955.

[37] J. H. Rappole and D. W. Warner, "Ecological aspects of migrant bird behavior in Veracruz, Mexico," in Migrant Birds in the Neotropics: Ecology, Behavior, Distribution, and Conservation, A. Keast and E. S. Morton, Eds., pp. 353-393, Smithsonian Institution Press, Washington, DC, USA, 1980.

[38] R. Greenberg, D. K. Niven, S. Hopp, and C. Boone, "Frugivory and coexistence in a resident and a migratory vireo on the Yucatan Peninsula," Condor, vol. 95, no. 4, pp. 990-999, 1993.

[39] T. H. Hamilton, "Adaptive variation in the genus Vireo," Wilson Bulletin, vol. 70, pp. 306-345, 1958. 
[40] B. L. Van Roo, E. D. Ketterson, and P. J. Sharp, “Testosterone and prolactin in two songbirds that differ in paternal care: the blue-headed vireo and the red-eyed vireo," Hormones and Behavior, vol. 44, no. 5, pp. 435-441, 2003.

[41] E. S. Morton, B. M. J. Stutchbury, and I. Chiver, "Parental conflict and brood desertion by females in blue-headed vireos," Behavioral Ecology and Sociobiology, vol. 64, pp. 947954, 2010.

[42] R. Greenberg and J. S. Ortiz, "Interspecific defense of pasture trees by wintering yellow warblers," Auk, vol. 111, no. 3, pp. 672-682, 1994.

[43] D. L. Neudorf and S. A. Tarof, "The role of chip calls in winter territoriality of yellow warblers," Journal of Field Ornithology, vol. 69, no. 1, pp. 30-36, 1998. 

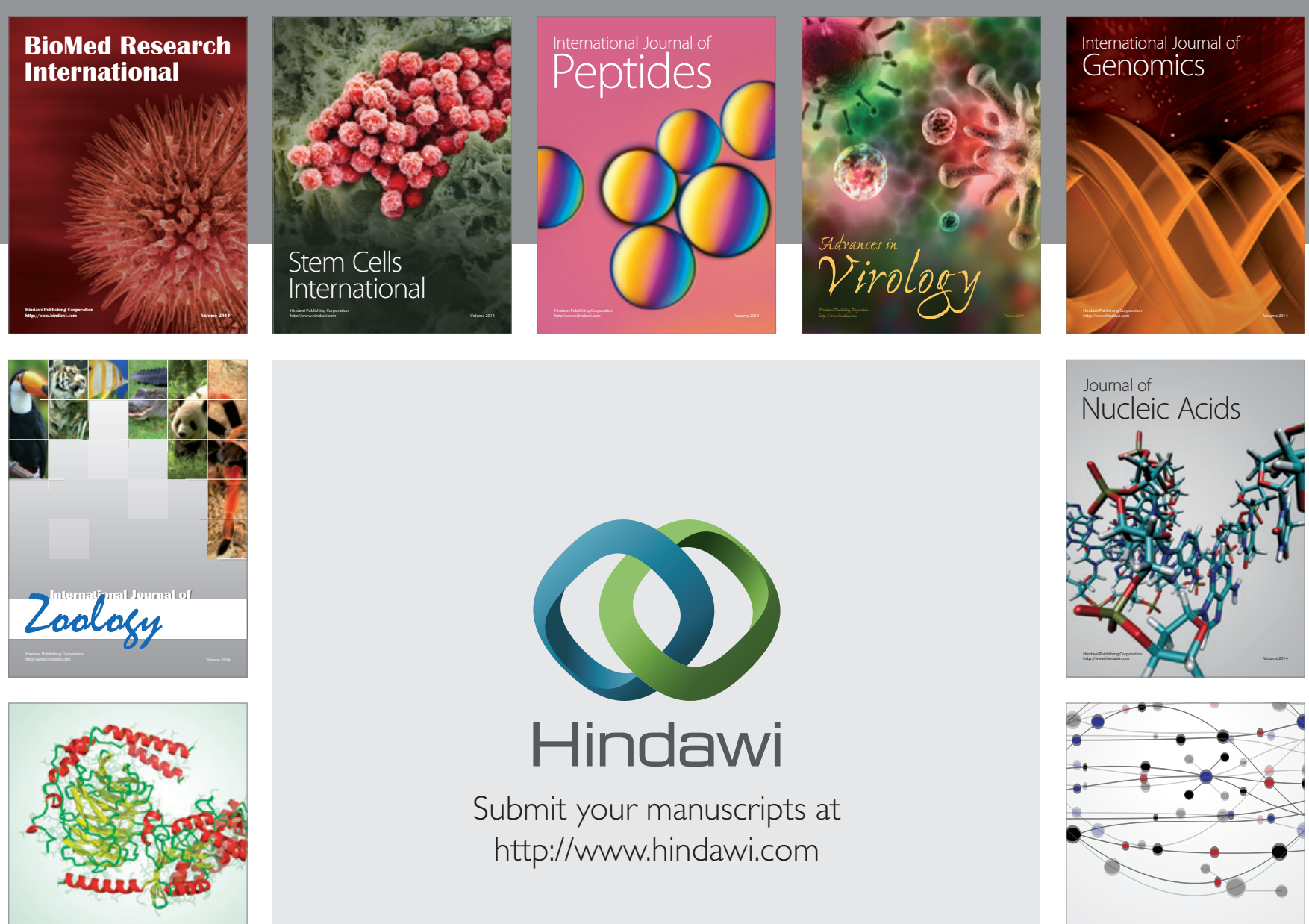

Submit your manuscripts at

http://www.hindawi.com

Signal ${ }^{\text {Jumal }}$ Transduction
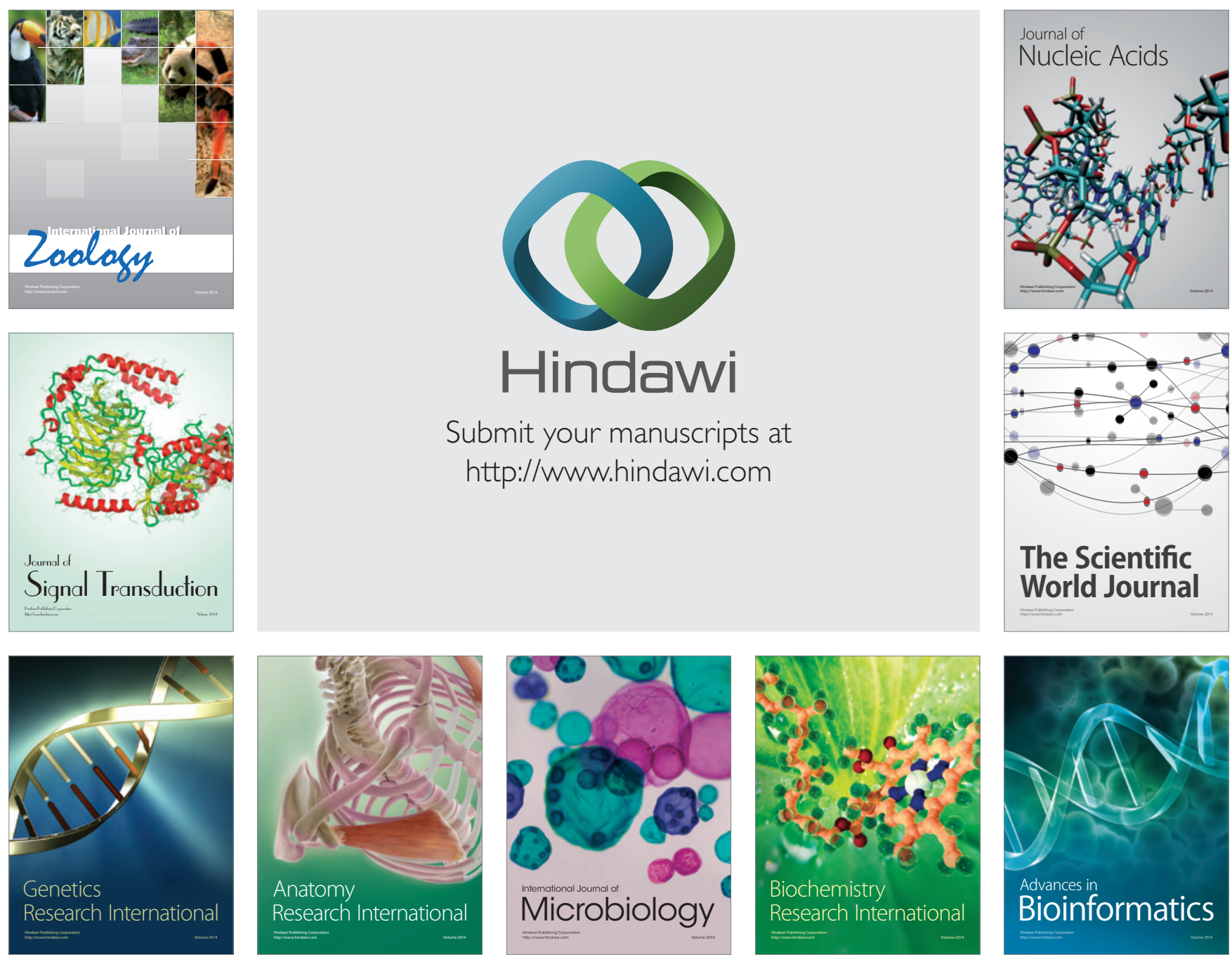

The Scientific World Journal
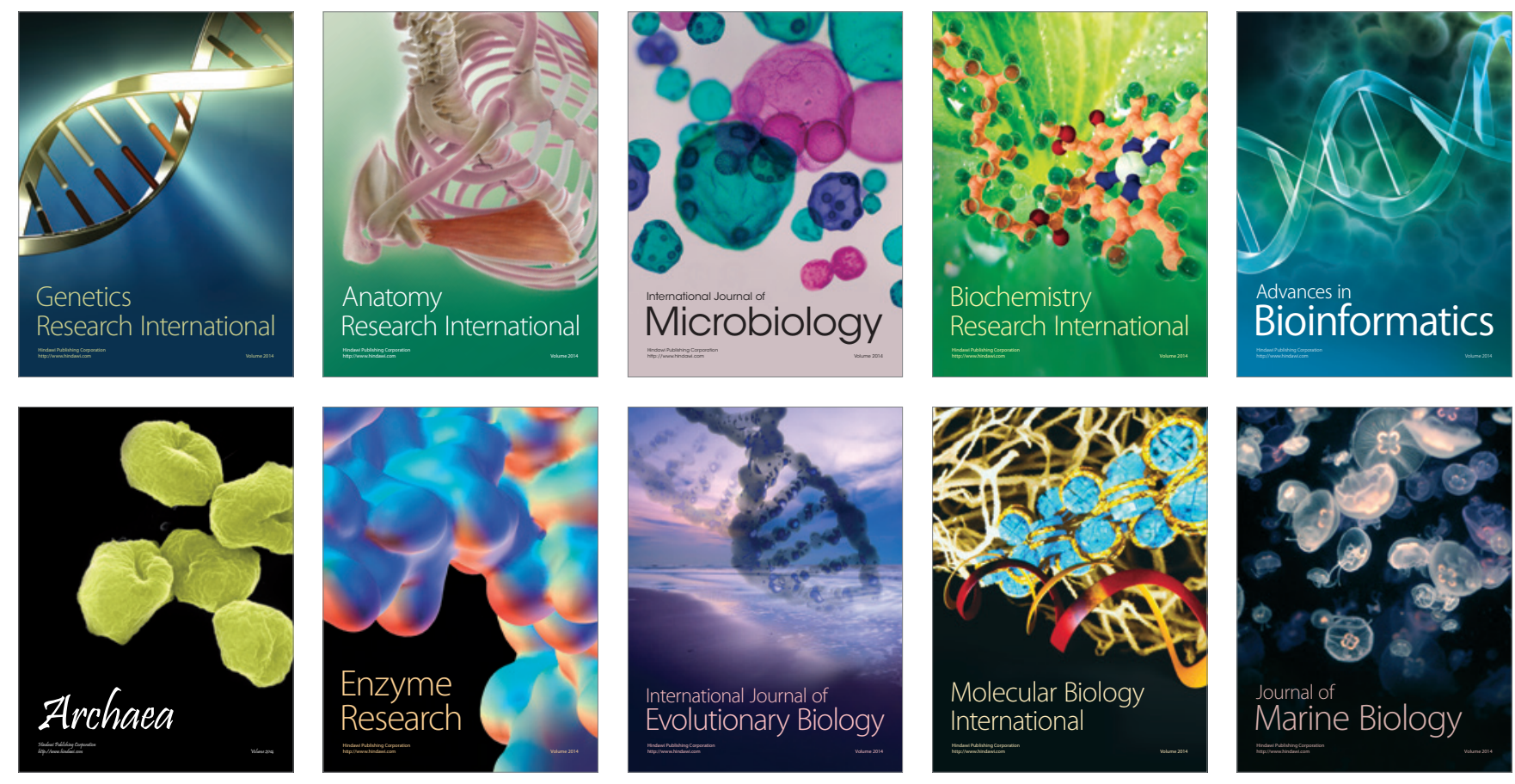